\title{
Simultaneous Detection of Five Pathogens from Cerebrospinal Fluid Specimens Using Luminex Technology
}

\author{
Linfu Zhou ${ }^{1,2, \dagger}$, Rui Wu ${ }^{1,+}{ }^{\dagger}$ Xiaodan Shi ${ }^{1}$, Dongyun Feng ${ }^{1}$, Guodong Feng ${ }^{1}$, Yining Yang ${ }^{1}$, \\ Wen Dai ${ }^{1}$, Ting Bian ${ }^{1}$, Tingting Liu ${ }^{1}$, Ying He ${ }^{1}$, Ming Shi ${ }^{1, *}$ and Gang Zhao ${ }^{1, *}$ \\ 1 Department of Neurology, Xijing Hospital, Fourth Military Medical University, Xi'an 710032, China; \\ zhoelfu@163.com (L.Z.); wurui1124@126.com (R.W.); shixd999@163.com (X.S.); fengdy@fmmu.edu.cn (D.F.); \\ fgd2000@fmmu.edu.cn (G.F.); yiningyang80@163.com (Y.Y.); wwdd126@126.com (W.D.); \\ bianting-44@163.com (T.B.); miracle6tt@163.com (T.L.); skyblue20090802@163.com (Y.H.) \\ 2 Department of Neurology, Third Hospital of People's Liberation Army, Baoji 721004, China \\ * Correspondences: biomidas@163.com (M.S.); zhaogang@fmmu.edu.cn (G.Z.); \\ Tel.: +86-29-84775361 (M.S. \& G.Z.) \\ + These authors contributed equally to this work.
}

Academic Editor: Paul B. Tchounwou

Received: 5 December 2015; Accepted: 29 January 2016; Published: 4 February 2016

\begin{abstract}
Early diagnosis and treatment are crucial for the outcome of central nervous system (CNS) infections. In this study, we developed a multiplex PCR-Luminex assay for the simultaneous detection of five major pathogens, including Mycobacterium tuberculosis, Cryptococcus neoformans, Streptococcus pneumoniae, and herpes simplex virus types 1 and 2, which frequently cause CNS infections. Through the hybridization reaction between multiplex PCR-amplified targets and oligonucleotide "anti-TAG" sequences, we found that the PCR-Luminex assay could detect as low as $10^{1}-10^{2}$ copies of synthetic pathogen DNAs. Furthermore, 163 cerebrospinal fluid (CSF) specimens from patients with suspected CNS infections were used to evaluate the efficiency of this multiplex PCR-Luminex method. Compared with Ziehl-Neelsen stain, this assay showed a high diagnostic accuracy for tuberculosis meningitis (sensitivity, 90.7\% and specificity, 99.1\%). For cryptococcal meningitis, the sensitivity and specificity were $92 \%$ and $97.1 \%$, respectively, compared with the May Grunwald Giemsa (MGG) stain. For herpes simplex virus types 1 and 2 encephalitis, the sensitivities were $80.8 \%$ and $100 \%$, and the specificities were $94.2 \%$ and $99 \%$, respectively, compared with Enzyme Linked Immunosorbent Assay (ELISA) assays. Taken together, this multiplex PCR-Luminex assay showed potential efficiency for the simultaneous detection of five pathogens and may be a promising supplement to conventional methods for diagnosing CNS infections.
\end{abstract}

Keywords: Luminex technology; multiplex PCR; central nervous system infections; cerebrospinal fluid

\section{Introduction}

CNS infections caused by viruses, bacteria, fungi, parasites and prions still remain diseases with significant morbidity and mortality [1,2]. In many developing countries affected by endemic diseases such as tuberculosis, HIV / AIDS, and cryptococcal meningitis, delayed diagnosis, treatment and high economic burden often lead to avoidable deaths or severe sequelae [3]. To reduce the mortality and improve the cure rates, it is vital to screen and identify pathogens in clinical specimens from patients as early as possible [4,5]. Early and accurate diagnosis will support physicians with the selection of the appropriate antimicrobial agents [6,7]. Most laboratory methods for diagnosing CNS infections 
are mainly based on the identification of pathogens by staining or cultures, the detection of specific antigens and antibodies, or the examination of pathogen nucleic acids with polymerase chain reaction (PCR) in CSF [8,9]. Microscopy of CSF is a widely applied rapid diagnostic technique, however, the time investment is not feasible in most busy routine diagnostic laboratories, where it has been shown increasing the examination time of CSF smears is necessary for improving sensitivity [10-12]. Although diagnosis based on culture is the reference standard, the clinical value of culture technique is limited due to its low sensitivity and long time consumption [13]. Previous studies have showed that multiplex PCR shows high sensitivity and specificity for the detection of pathogens [14-16], however, this method may be difficult to implement with rigorous quality controls, and becomes more challenging notably in terms of low numbers of microorganisms in CSF specimens [13,17]. Moreover, the throughput of PCR method is relatively limited since only a few genes can be detected in a single reaction [14,16-19].

Luminex technology is a multi-plex assay characterized with high-throughput, accuracy, high speed, sensitivity and specificity, which can qualitatively and quantitatively analyze and report up to 100 different reactions in a single reaction vessel [20-24]. Previous studies have reported that this technology offered a new platform for high-throughput nucleic acid detection which is being used in infectious diseases [25-28].

In the present study, we developed a rapid, high-throughput diagnostic method integrated multiplex PCR and Luminex technology for detecting five pathogens, including M. tuberculosis, C. neoformans, S. pneumoniae, herpes simplex virus types 1 (HSV-1) and 2 (HSV-2), which account for more than $70 \%$ of CNS infections in Northwest China. Moreover, we applied this method to detect the five pathogens simultaneously in a large number of CSF specimens from suspected CNS infection patients in Xijing Hospital, one of the biggest hospitals in China's Northwest Region, where approximately 120,000 outpatients with neurological diseases are treated annually, among which around 4000 were suspected of CNS infections.

\section{Materials and Methods}

\subsection{Viral and Bacterial Strains}

Five pathogenic strains, including M. tuberculosis strain H37Rv, C. neoformans strain H99, S. pneumoniae strain D39 (Center for Clinical Laboratory Medicine of Xijing Hospital, the Fourth Military Medical University), HSV-1 strain SM44 (Department of Microbiology, the Fourth Military Medical University), HSV-2 strain MS (The National Center for Microbial Engineering Detection, Northwest University), were used in the study.

\subsection{Clinical Specimens}

A total of 163 CSF specimens were collected from 1996 to 2013 at the CSF Laboratory of Xijing Hospital for Central Nervous Infectious Diseases in Shaanxi Province, China. Briefly, $2 \mathrm{~mL}$ of CSF was centrifuged at $3000 \times g$ for $15 \mathrm{~min}$, and the sediment was smeared on slides as previously described [29]. All smears were stained by the Ziehl-Neelsen stain [29,30], MGG stain [31] and Gram stain for the presence of M. tuberculosis, C. neoformans and S. pneumoniae and observed under a light microscope. Furthermore, all the CSF specimens were also tested for HSV-1 and HSV-2 with a commercial ELISA assay. Among them, 54 CSF specimens were obtained from patients with definite tuberculosis meningitis [32], defined as a clinical syndrome consistent with tuberculosis meningitis, with Ziehl-Neelsen stain positive or M. tuberculosis isolated in CSF Mycobacteria Growth Indicator Tube (MGIT 960) system culture. Twenty five CSF specimens from patients with cryptococcal meningitis were definitely diagnosed by MGG stain. Twenty seven CSF specimens from patients with HSV-1 and HSV-2 encephalitis were identified by a commercial ELISA assay. The remaining 57 CSF specimens, showing negative results by either Ziehl-Neelsen stain, MGG stain, Gram stain or ELISA detection, 
were also used in this study. In addition, 20 CSF specimens from non-infected patients such as cerebral infarction, cerebral hemorrhage, Alzheimer's and Parkinson's disease were also analyzed.

\subsection{Primer}

Four sets of primers were designed using the Oligo6.5 software. The primer for S. pneumoniae was cited in a previous study [33]. The GenBank reference sequence GIs applied for the primer design were CP009480.1 for M. tuberculosis, L38588.1 for C. neoformans, AF467249.1 for S. pneumoniae, X14112.1 for HSV-1, and Z86099.2 for HSV-2. Each forward primer was modified by an unique 24 base oligonucleotide "TAG" sequence at 5 ' terminus which is captured to MagPlex-TAG microsphere with a complementary "anti-TAG" sequence. The "TAG" sequence was separated from the sequence specific portion of the primer with an internal spacer for 12-carbon amine. Reverse primer was biotinylated at $5^{\prime}$ terminus (see Appendix Figure A1). The MagPlex-TAG microspheres were purchased from Luminex Corporation. All primers were synthesized by Takara Biotechnology (Dalian, China), and their sequences are listed in Table 1.

Table 1. The specific primers used in multiplex PCR with Luminex assay.

\begin{tabular}{|c|c|c|c|c|c|}
\hline Organism & $\begin{array}{l}\text { GenBank } \\
\text { Accession No. }\end{array}$ & $\begin{array}{l}\text { Target } \\
\text { Gene }\end{array}$ & Oligonucleotide Sequence of Primer $\left(5^{\prime}-3^{\prime}\right)$ & $\begin{array}{l}\text { Length } \\
\text { (bp) }\end{array}$ & Position $\left(5^{\prime}-3^{\prime}\right)$ \\
\hline M. tuberculosis & СР009480.1 & IS986 & $\begin{array}{l}\text { F- CTTAACATTTAACTTCTATAACAC-12C- } \\
\text { CGTGAGGGCATCGAGGTGGC } \\
\text { R-biotin-GCGTAGGCGTCGGTGACAAA } \\
\text { F- CACTTAATTCATTCTAAATCTATC-12C- }\end{array}$ & 245 & $889650-889894$ \\
\hline C. neoformans & L38588.1 & URA & $\begin{array}{l}\text { TGTCCTAACCAGTGCGACAGCGATG } \\
\text { R-biotin-GTACTTCCTGACCTCTTGCAGCTCC } \\
\text { F- ATTAAACAACTCTTAACTACACAA-12C- }\end{array}$ & 360 & $390-749$ \\
\hline S. pneumoniae & AF467249.1 & lytA & $\begin{array}{l}\text { CGCAATCTAGCAGATGAAGCAGGTT } \\
\text { R-biotin-AAGGGTCAACGTGGTCTGAGTGGTT } \\
\text { F- TACATTCAACACTCTTAAATCAAA-12C- }\end{array}$ & 124 & $328-451$ \\
\hline HSV-1 & X14112.1 & Gene 42 & $\begin{array}{l}\text { GCCGTTGAGCTAGCCAGCGA } \\
\text { R-biotin-GTGCTGGTGCTGGACGACAC } \\
\text { F- ACTACTTATTCTCAAACTCTAATA-12C- }\end{array}$ & 257 & $93557-93813$ \\
\hline HSV-2 & Z86099.2 & TK & $\begin{array}{l}\text { GTAAGCGCGGGCCAAAGGAT } \\
\text { R-biotin-TCAAACACGGAAGCCCGAAC }\end{array}$ & 234 & $46635-46868$ \\
\hline
\end{tabular}

$\mathrm{F}$ = forward, $\mathrm{R}=$ reverse. Unique 24 base oligonucleotide "TAG" sequences and 12-carbon amine containing group are indicated by underline and bold, respectively. R-primers were biotinylated at $5^{\prime}$ terminus. HSV-1 and HSV-2, herpes simplex virus types 1 and 2 .

\subsection{Plasmid Preparation}

We synthesized 245, 360, 124, 257 and 234 bp sequences of the conserved regions of $M$. tuberculosis, C. neoformans, S. pneumoniae, HSV-1 and HSV-2, respectively. The nucleic acids were cloned into pUC57 plasmid (Sangon, Shanghai, China). Then these plasmids were transformed into Escherichia coli (DH5a), and plasmid DNAs were extracted with E.Z.N.A DNA mini Kit I (Omega, Doraville, GA, USA). OD value was measured by UV spectrophotometer (Eppendorf, city, Germany). Copy numbers were calculated from the formula: $\left(6.02 \times 10^{23}\right) \times\left(\mathrm{X} \mathrm{ng} / \mu \mathrm{L} \times 10^{-9}\right) /($ DNA length $\times 660)=$ copies $/ \mu \mathrm{L}$ ( $\mathrm{X}$ was the concentration of the plasmid). For subsequent experiment, five plasmid DNAs used in this study were prepared with 10-fold serial dilutions.

\subsection{DNA Extraction and PCR Amplification}

CSF specimens with volumes ranged from 200 to $400 \mu \mathrm{L}$ were stored at $-20^{\circ} \mathrm{C}$. After thawing the CSF samples, they were centrifuged for $15 \mathrm{~min}$ at 13,000 $\times g$ and the supernatant was removed. Four hundred microliters of distilled water was added, and the pellet was resuspended. And then, pathogen genomic DNA was extracted by using E.Z.N.A. MicroElute Genomic DNA Kit (Omega, Doraville, GA, USA), according to the manufacturer's instructions. DNA was eluted in $30 \mu \mathrm{L}$ elution buffer and was subsequently stored at $-20^{\circ} \mathrm{C}$, and thawed once just before use. The multiplex PCR amplification was performed in a total volume of $25 \mu \mathrm{L}$ containing the following: $1 \times$ multiplex master mix (Qiagen, Ballerup, Denmark), $8 \mu \mathrm{L}$ genomic DNA template and $200 \mathrm{nM}$ of each primer (Takara, 
Dalian, Liaoning, China) (Table 1), Positive control just needed $1 \mu \mathrm{L}$ (80-130 ng) plasmid DNA and distilled water was used as a negative control. Amplification conditions were as follows: $95^{\circ} \mathrm{C}$ for $5 \mathrm{~min}$, followed by 35 cycles of $94^{\circ} \mathrm{C}$ for $30 \mathrm{~s}, 59^{\circ} \mathrm{C}$ for $90 \mathrm{~s}$, and $72{ }^{\circ} \mathrm{C}$ for $30 \mathrm{~s}$, and a final extension step of $72{ }^{\circ} \mathrm{C}$ for $10 \mathrm{~min}$, and stored at $4{ }^{\circ} \mathrm{C}$.

\subsection{PCR Product Identification and Luminex Assay}

PCR products were visualized by $1.5 \%$ agarose gel electrophoresis to examine the amplified DNA. The target PCR products for M. tuberculosis, C. neoformans, S. pneumoniae, HSV-1 and HSV-2 were 245, $360,124,257$ and $234 \mathrm{bp}$, respectively. And these target gene fragments could also be obtained by PCR amplification of the genomic DNA from five pathogen strains.

The PCR-Luminex assay procedure is available at the Luminex Corporation website (http://info.luminexcorp.com/download-the-xmap-cookbook). Briefly, MagPlex-TAG microspheres sets were prepared and resuspended by sonication and vortex for approximately $20 \mathrm{~s}$, and then a Working Microsphere Mixture was prepared by diluting the MagPlex-TAG microspheres stocks to 100 microspheres of each set/ $\mu \mathrm{L}$ in $2 \times$ Tm Hybridization Buffer $(0.4 \mathrm{M} \mathrm{NaCl}, 0.2 \mathrm{M}$ Tris, $0.16 \%$ Triton $\mathrm{X}-100, \mathrm{pH} 8.0$, Molecular Grade $\mathrm{dH}_{2} \mathrm{O}$ ) by vortex for $20 \mathrm{~s}$. Subsequently, $25 \mu \mathrm{L}$ of MagPlex-TAG microspheres Mixture was added in each sample or background well and $25 \mu \mathrm{L}$ distilled water was added in each background well. For each sample well, $7 \mu \mathrm{L}$ amplified biotinylated PCR products and distilled water were added to a total volume of $50 \mu \mathrm{L}$. The mixtures were incubated at $96^{\circ} \mathrm{C}$ for $90 \mathrm{~s}$ and then hybridized in a thermocycler for $30 \mathrm{~min}$ at $37^{\circ} \mathrm{C}$.

After the beads were pelleted, the supernatant was removed by using vacuum manifold (Luminex, Austin, TX, USA). And the pelleted microspheres were washed twice with $200 \mu \mathrm{L} 1 \times$ Tm Hybridization Buffer. Fresh reporter mix $(75 \mu \mathrm{L})$ was prepared by diluting Streptavidin, R-Phycoerythrin Conjugate (SA-PE, Invitrogen, Carlsbad, CA, USA) to $5 \mu \mathrm{g} / \mathrm{mL}$ in $1 \times \mathrm{Tm}$ Hybridization Buffer. The Bead-PCR product-SAPE mixtures were incubated at $37^{\circ} \mathrm{C}$ in dark for $15 \mathrm{~min}$ and analyzed on the Luminex 200 analyzer (Luminex Corporation) according to the system manual. The sample size was set to $50 \mu \mathrm{L}$ with a minimum of 50 beads per target analyzed. Each microsphere was analyzed by a red laser which identified the color of the microsphere and a green laser which analyzed the surface content of the SA-PE bound to the hybridized PCR products $[23,24,33]$.

\subsection{Determination of Cutoff Values and Data Analysis}

The data were reported as median fluorescence intensity (MFI) and exported from the Luminex instrument. The determination of cutoff values were based on previous studies [33,34], which obtained from the median fluorescence intensities of 55 no-template controls (NTCs) run during the study period. We calculated a corrected MFI (cMFI), which normalizes to negative control fluorescence as follows: $\mathrm{cMFI}=(\mathrm{MFI}$ (sample) - MFI (negative control))/MFI (negative control). The cutoff cMFI chosen was three times the 95th percentile for the each pathogen. The MFI values of samples were shown as mean \pm SEM and then analyzed using OriginPro 8.0 software. Additionally, the consistency check was performed using Cohen's kappa test for SPSS17.0 software.

\section{Results}

\subsection{Specificity of Primers}

Using plasmid DNAs, five sets of specific primers were confirmed by single nucleic acid amplification. Single PCR results showed that all the target gene fragments can be obtained by $1.5 \%$ agarose gel electrophoresis, and no cross-reactions were found (data not shown). 


\subsection{Determination of Amplification Conditions for Five-Plex PCR}

Next we applied a five-plex PCR Reaction System to amplify the plasmid DNAs to test the efficiency of the system. Agarose gel electrophoresis analysis (Figure 1) showed that this multiplex PCR system was feasible and could accomplish an effective amplification for each plasmid.

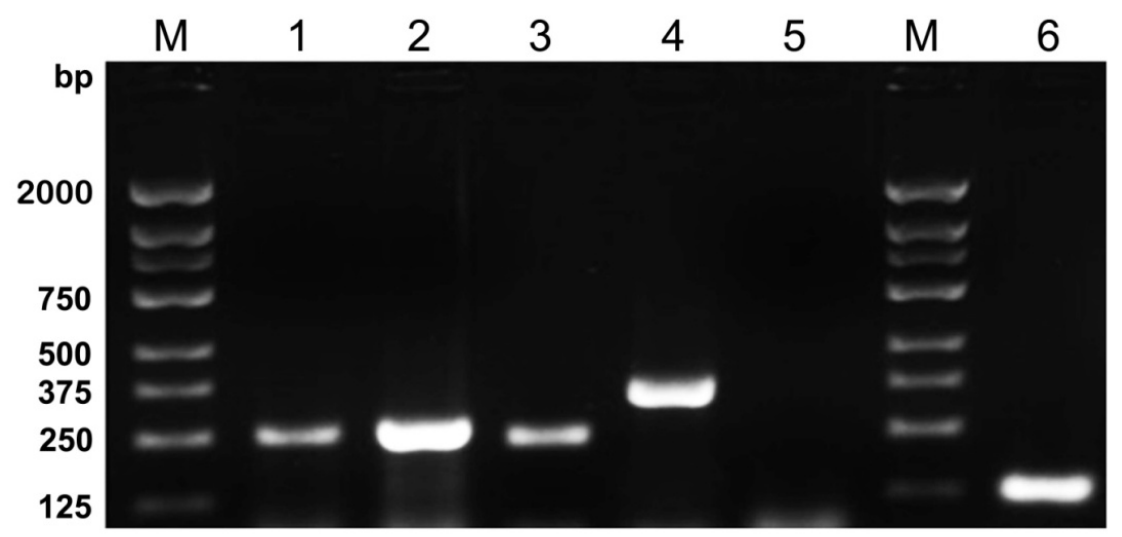

Figure 1. Agarose gel electrophoresis showed the results of five-plex PCR amplification followed by M. tuberculosis, HSV-1, HSV-2, C. neoformans and S. pneumoniae plasmid DNAs, respectively. Each plasmid DNAs was successfully amplified by five-plex PCR Reaction System. Lanes are as follows: M, DNA Marker 2000; 1, M. tuberculosis 245 bp; 2, HSV-1 257 bp; 3, HSV-2 234 bp; 4, C. neoformans $360 \mathrm{bp} ; 5$, negative control; 6 , S. pneumoniae $124 \mathrm{bp}$.

\subsection{Analytical Specificity of PCR-Luminex Assay}

The Luminex assay of multiplex PCR products for each plasmid DNAs (Figure 2) showed a single and specific fluorescence signal. For two plasmid DNAs as templates, the two different specific fluorescence values were detected through multiplex PCR-Luminex assay. Moreover, multiple specific fluorescence values could be obtained from various mixed templates, indicating that PCR products were only hybridized with oligonucleotide "anti-TAG" sequences on the corresponding microspheres in the same testing system.

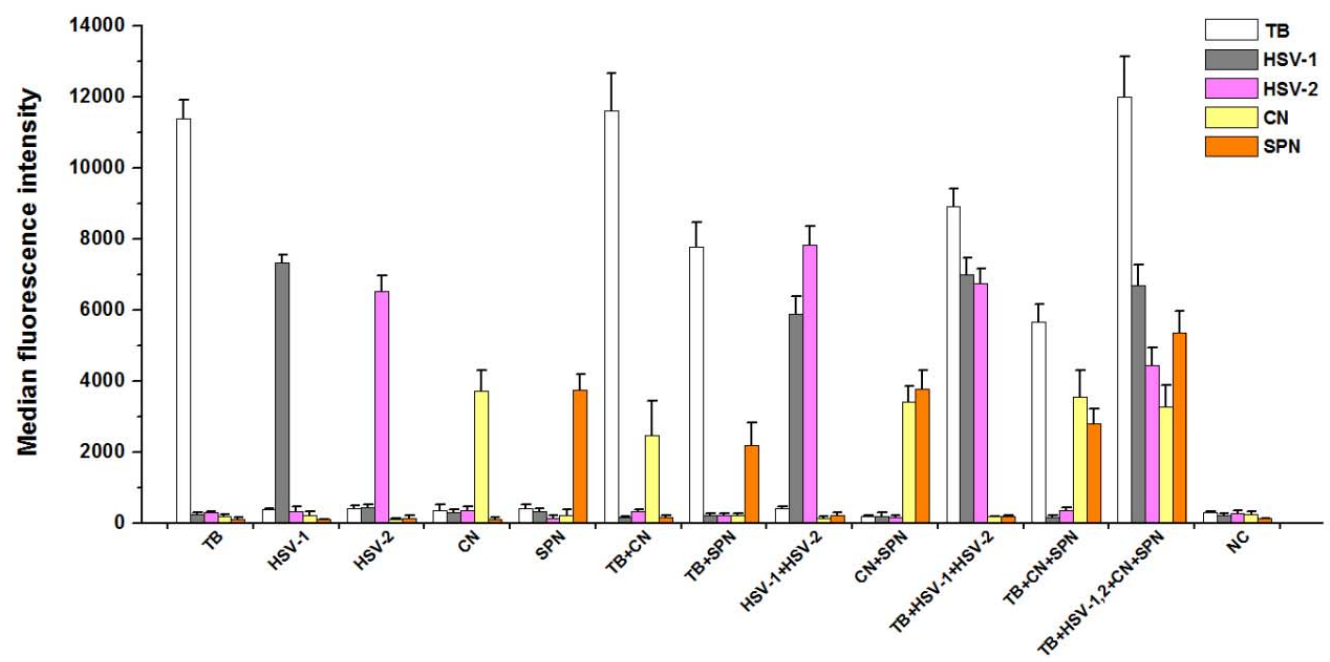

Figure 2. Detection of target products by the five-plex PCR-Luminex showed a high specificitity. Distilled water was used as the negative control (NC). Each bar represents the average MFI of triplicate samples. The error bars indicate standard deviations. TB, M. tuberculosis; CN, C. neoformans; SPN, S. pneumoniae; HSV-1 and HSV-2, herpes simplex virus types 1 and 2. 


\subsection{Analytical Sensitivity of PCR-Luminex Assay}

The sensitivity of the PCR-Luminex assays was assessed by testing serial dilutions of five plasmid DNAs for M. tuberculosis, HSV-1, HSV-2, C. neoformans and S. pneumoniae. The tests were performed at each concentration of plasmid, with distilled water used as NC. The results showed that the limit of detection was $10^{2}$ plasmid copies for M. tuberculosis, C. neoformans, HSV-2 and S. pneumoniae and $10^{1}$ plasmid copies for HSV-1 (Table 2). The sensitivity of the assay for HSV-1 was higher than the others. All detects were evaluated with the single-plex amplicons in multiplex PCR and performed for three times.

Table 2. Analytical sensitivity of serial dilution plasmid.

\begin{tabular}{ccc}
\hline Organism & Plasmid Quantity (Copies) & cMFI \\
\hline M. $t$ uberculosis & $10^{8}$ & $16.95 \pm 0.45$ \\
& $10^{6}$ & $10.06 \pm 0.22$ \\
$10^{4}$ & $7.49 \pm 0.30$ \\
$10^{2}$ & $6.79 \pm 0.20$ \\
HSV-1 & $10^{1}$ & $0.93 \pm 0.07$ \\
& $10^{2}$ & $11.41 \pm 0.72$ \\
& 50 & $6.56 \pm 0.20$ \\
& 10 & $5.30 \pm 0.31$ \\
HSV-2 & 5 & $2.30 \pm 0.12$ \\
& 1 & $2.45 \pm 0.15$ \\
& $10^{8}$ & $17.72 \pm 0.59$ \\
& $10^{6}$ & $7.14 \pm 0.38$ \\
& $10^{4}$ & $6.19 \pm 0.14$ \\
& $10^{2}$ & $3.49 \pm 0.07$ \\
& $10^{1}$ & $2.25 \pm 0.02$ \\
& $10^{8}$ & $34.80 \pm 0.21$ \\
& $10^{6}$ & $31.86 \pm 0.18$ \\
& $10^{4}$ & $28.29 \pm 0.45$ \\
& $10^{2}$ & $9.62 \pm 0.12$ \\
& $10^{1}$ & $1.23 \pm 0.10$ \\
& $10^{8}$ & $8.78 \pm 0.47$ \\
& $10^{6}$ & $6.15 \pm 0.36$ \\
& $10^{4}$ & $4.94 \pm 0.29$ \\
& $10^{2}$ & $3.77 \pm 0.22$ \\
& $10^{1}$ & $2.18 \pm 0.14$
\end{tabular}

Cutoff cMFI $=3.0$. All samples were performed in triplicate. If the results from a duplicate sample analysis exceeded the Cutoff cMFI, the sample was defined as PCR-Luminex assay positive.

\subsection{Assessment of PCR-Luminex Performance Using CSF Specimens}

Then we applied this multiplex PCR-Luminex method to examine 163 CSF specimens from patients with suspected CNS infections. We found that according to the cutoff cMFI, 113 CSF specimens were positive by PCR-Luminex assay. Of these, 50 were positive for M. tuberculosis, 27 were positive for C. neoformans, 29 were positive for HSV-1 and two were positive for HSV-2. In addition, five specimens infected with $S$. pneumoniae were also found. The detection results for pathogens obtained by microscopy, ELISA and PCR-Luminex assay are shown in Tables 3-5. For tuberculosis meningitis, 49 of 54 specimens confirmed by Ziehl-Neelsen stain were detected positive following PCR-Luminex assay which were true positive. Among the CSF specimens showing negative results by either Ziehl-Neelsen stain, MGG stain, Gram stain or ELISA detection, one was found false-positive. Comparing with Ziehl-Neelsen stain, the sensitivity and specificity of PCR-Luminex assay were 90.7\% (49/54) and 99.1\% (108/109), respectively (Table 3). The results of PCR-Luminex assay and Ziehl-Neelsen stain for matching were compared by using kappa test $(k=0.9153)$. According to MGG stain, the "gold standard" for cryptococcal meningitis, 23 of 25 PCR-Luminex positive specimens 
were true positives and four were false positives. Our results demonstrated that the sensitivity and specificity for cryptococcal meningitis were $92 \%(23 / 25)$ and $97.1 \%(134 / 138)$, respectively (Table 4$)$. The two methods showed good consistency $(k=0.8628)$, suggesting that PCR-Luminex assay matching was in agreement with MGG stain. Based on results from ELISA as the reference test, HSV-1 for PCR-Luminex assay had diagnostic sensitivity and specificity of 80.8\% (21/26) and 94.2\% (129/137), respectively (Table 5). The consistency check showed that $k$ coefficient of the two methods was 0.7158 . For HSV-2, one sample which was positive for ELISA was detected positive, and another sample for ELISA negative gave a positive result when tested with PCR-Luminex assay (Table 5). In addition, the S. pneumoniae subassay also identified five specimens with suspected CNS infections (Data not shown).

Table 3. M. tuberculosis detected by PCR-Luminex assay vs. indirect smear microscopy.

\begin{tabular}{cccccc}
\hline PCR-Luminex & Smear Positive & Smear Negative & Sensitivity & Specificity & Kappa \\
\hline$(+)$ & 49 & 1 & $90.7 \%$ & $99.1 \%$ & 0.9153 \\
$(-)$ & 5 & 108 & & & \\
\hline
\end{tabular}

Table 4. C. neoformans detected by PCR-Luminex assay vs. MGG stain.

\begin{tabular}{cccccc}
\hline PCR-Luminex & MGG Positive & MGG Negative & Sensitivity & Specificity & Kappa \\
\hline$(+)$ & 23 & 4 & $92 \%$ & $97.1 \%$ & 0.8628 \\
$(-)$ & 2 & 134 & & \\
\hline \multicolumn{5}{c}{ MGG, May Grunwald Giemsa stain. }
\end{tabular}

Table 5. HSV-1 or HSV-2 detected by PCR-Luminex assay vs. ELISA assay.

\begin{tabular}{ccccccc}
\hline \multicolumn{2}{c}{ PCR-Luminex } & ELISA Positive & ELISA Negative & Sensitivity & Specificity & Kappa \\
\hline \multirow{2}{*}{ HSV-1 } & $(+)$ & 21 & 8 & $80.8 \%$ & $94.2 \%$ & 0.7158 \\
& $(-)$ & 5 & 129 & & & \\
\hline \multirow{2}{*}{ HSV-2 } & $(+)$ & 1 & 1 & $100 \%$ & $99 \%$ & 0.6639 \\
& $(-)$ & 0 & 161 & & & \\
\hline
\end{tabular}

ELISA, Enzyme linked immunosorbent assay.

\section{Discussion}

In this report, the Luminex-based strategy for multiplex detection of pathogen nucleic acids was a useful method for diagnosis of CNS infections, which could be utilized to identify five different pathogens in CSF specimens simultaneously. Using PCR-Luminex technique we examined the specificity and sensitivity of this assay, the results showed that this detection system had specificity and sensitivity comparable to the conventional diagnostic methods. Our present study also showed that the target PCR products were only hybridized with the oligonucleotide "anti-TAG" sequences on the corresponding microspheres in the testing system and non-specific reactions were not found, consistent with previous studies [25,35,36]. Moreover, we also found that the limit of detection sensitivity revealed detection of as low as $10^{1}-10^{2}$ copies of plasmid DNAs. Hence, these findings suggest that the development of the multiplex detection platform based on PCR-Luminex technology for screening five pathogens is actionable.

Previous studies [37-40] showed that the sensitivity and specificity of Luminex technology detection are mainly relied on the designing and synthesizing for specific primers and probes, which are the key and prerequisite for construction of gene chips. Specific primers can ensure the stability of the experiment and reduce non-specific reactions occurrences. Consequently, the GC content of the primers we designed in our experiments were all between $55 \%$ and $60 \%$, and the annealing temperature were between $55^{\circ} \mathrm{C}$ and $60^{\circ} \mathrm{C}$ as well. Then, the results showed that all the primers were designed appropriately and ensured that the five target fragments could be amplified simultaneously. 
Wilson et al., [41] reported that ten-plex PCR-coupled liquid bead array detected lower sensitivity than the single PCR. Thus, it is indispensable for us to optimize the conditions of multiplex PCR reaction. To ensure the specificity and sensitivity of the assay, we also performed the optimizing experiments for hybridization reaction conditions and confirmed $37^{\circ} \mathrm{C}$ was the optimal hybridization temperature and 30 minutes as the optimum hybridization time. Like with previous studies $[23,26,42]$, using MagPlex-TAG microspheres in the experiment could guarantee the same annealing temperature, and effectively avoid cross-hybridization. A total of 163 CSF specimens collected over 10 years from patients with suspected CNS infections were examined, and we found 113 specimens were detected positive by PCR-Luminex analysis. Of these, $94(88.7 \%)$ could be defined as true-positive, which were positive by conventional diagnostic methods as well as the PCR-Luminex assay. When the performance of this assay was assessed with clinical specimens previously tested positive by conventional methods, we found that the assay had a relatively high diagnostic accuracy for tuberculosis meningitis, cryptococcal meningitis and HSV-1 and HSV-2 encephalitis, respectively. However, the CSF specimens had been stored at $-20^{\circ} \mathrm{C}$ for a long time (years) and a consequent false negative PCR-Luminex assay result might offer a likely explanation. Furthermore, the cutoff values were instead set by a practical method based on the values for the NTCs and based on the positive results for the samples by the conventional assay [33]. This might also lead to impaired sensitivity.

The multiplex PCR-Luminex system could simultaneously detect five pathogen nucleic acids in a single reaction and provide a high-throughput low-time consuming assay. Admittedly, in the present study the use of only only one primer set for each target may raise the possibility of false-negative results [35]. Like conventional PCR with open stages, the limitation of this approach is the potential to produce false-positive results due to cross-contamination with amplicons from the environment. Another drawback of the evaluation of the method was that we used frozen CSF specimens that had been stored for a long period of time, which may lead to an impaired sensitivity. The sensitivity would presumably be improved if fresh CSF specimens were used. Considering these, multiply primer sets, implementing standardized PCR laboratory procedures, increasing sample sizes, and specimen collection handling and processing should be adopted or improved in our future study.

\section{Conclusions}

Here we established a rapid and sensitive five-plex PCR-Luminex assay for simultaneous detection of five pathogens from CSF specimens in $3.5 \mathrm{~h}$. This approach might be a promising supplement to the conventional methods for diagnosing CNS infections.

Acknowledgments: The authors thank Xiuli Xu (Center for Clinical Laboratory Medicine of xijing hospital, the Fourth Military Medical University), Zhikai Xu (Department of Microbiology, the Fourth Military Medical University) and Jing Gao (The National Center for Microbial Engineering Detection, Northwest University) for providing experimental strains. We also thank the technical staff: Yining Yang, Wen Dai, Ting Bian, Tingting Liu and Ying He for their help with the clinical specimens processing. And the authors thank all the patients who were enrolled in the study.

Author Contributions: Linfu Zhou and Rui Wu designed and conducted the experiments, collected and analyzed the data, and wrote the paper. Ming Shi and Gang Zhao designed the experiments and contributed to revising the paper. Xiaodan Shi, Dongyun Feng, Guodong Feng, Yining Yang, Wen Dai, Ting Bian, Tingting Liu and Ying He conducted the experiments, collected and processed the clinical specimens.

Conflicts of Interest: The authors declare no conflict of interest. 


\section{Appendix}

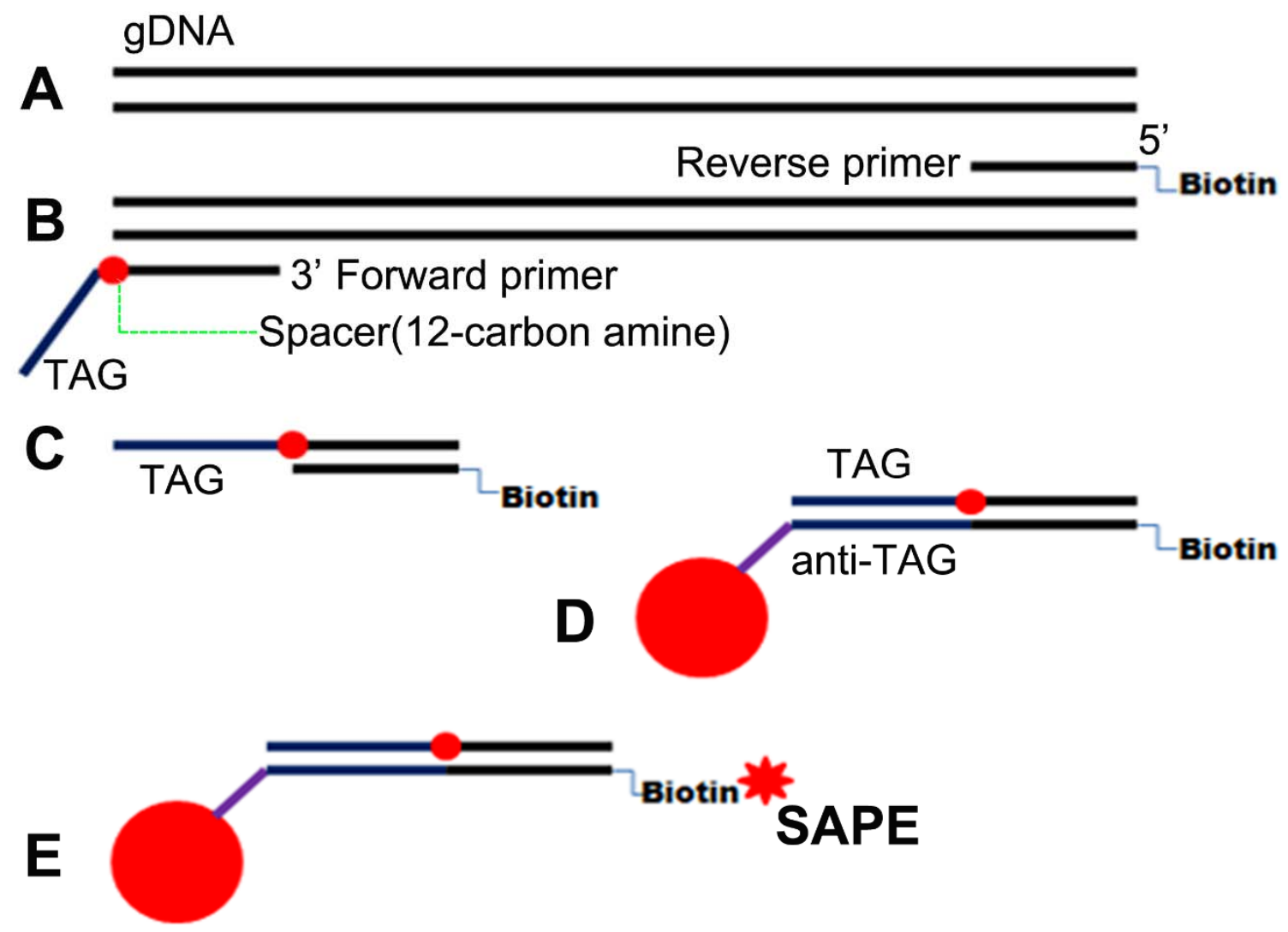

Figure A1. Schematics for multiplex PCR-luminex assay. (A) Genomic template DNA is firstly extracted from CSF specimens; (B) Reverse primer and forward primer are then labeled with biotin and an unique 24 base oligonucleotide "TAG" sequence at the 5 ' terminus, respectively. (C-E) When this "TAG" primer is combined with $5^{\prime}$ biotinylated reverse primer, a sequence specific double-stranded biotinylated amplicon is generated; (C) which is captured by a MagPlex-TAG microsphere through the hybridization of its "TAG" to its complementary "anti-TAG" sequence; (D) and then the captured amplicon is labeled with streptavidin-R-phycoerythrin (SAPE); (E) Finally, the fluorescent signal associated with each microsphere is measured by Luminex 200 analyzer.

\section{References}

1. Bautista, C. Central nervous system infections. Crit. Care Nurs. Clin. N. Am. 2013, 25, ix. [CrossRef] [PubMed]

2. Tan, Y.C.; Gill, A.K.; Kim, K.S. Treatment strategies for central nervous system infections: An update. Expert Opin. Pharmacother. 2015, 16, 187-203. [CrossRef] [PubMed]

3. Yansouni, C.P.; Bottieau, E.; Lutumba, P.; Winkler, A.S.; Lynen, L.; Buscher, P.; Jacobs, J.; Gillet, P.; Lejon, V.; Alirol, E.; et al. Rapid diagnostic tests for neurological infections in Central Africa. Lancet. Infect. Dis. 2013, 13, 546-558. [CrossRef]

4. Thomson, R.B., Jr.; Bertram, H. Laboratory diagnosis of central nervous system infections. Infect. Dis. Clin. N. Am. 2001, 15, 1047-1071. [CrossRef]

5. Kamei, S. Bacterial meningitis: Determination of pathogens and therapeutic management. Clin. Neurol. 2004, 44, 846-848.

6. Miner, J.R.; Heegaard, W.; Mapes, A.; Biros, M. Presentation, time to antibiotics, and mortality of patients with bacterial meningitis at an urban county medical center. J. Emerg. Med. 2001, 21, 387-392. [CrossRef] 
7. Nemeth, J.; Oesch, G.; Kuster, S.P. Bacteriostatic versus bactericidal antibiotics for patients with serious bacterial infections: Systematic review and meta-analysis. J. Antimicrob. Chemother. 2015, 70, 382-395. [CrossRef] [PubMed]

8. Morita, A. Clinical and laboratory diagnosis of central nervous system infections. Brain Nerve 2015, 67, 777-785. [PubMed]

9. Sussmuth, S.D.; Brettschneider, J.; Spreer, A.; Wick, M.; Jesse, S.; Lewerenz, J.; Otto, M.; Tumani, H. Current cerebrospinal fluid diagnostics for pathogen-related diseases. Der Nervenarzt 2013, 84, 229-244. [PubMed]

10. Cambanis, A.; Ramsay, A.; Wirkom, V.; Tata, E.; Cuevas, L.E. Investing time in microscopy: An opportunity to optimise smear-based case detection of tuberculosis. Int. J. Tuberc. Lung Dis. 2007, 11, 40-45. [PubMed]

11. Qing, X. Diagnosis and treatment of bacterial meningitis. Chin. J. Contemp. Neurol. Neurosurg. 2004, 8, 210-211.

12. Zhao, J.; Zhao, Y.; Ge, C.X.; Yu, M.H.; Ma, H.L. Comparison of several methods in the diagnosis of cryptococcal meningitis. J. Qiqihar Univ. Med. 2015, 11, 4442-4443.

13. Philip, N.; William, T.; William, D.V. Diagnosis of tuberculous meningitis: Challenges and promises. Malaysian J. Pathol. 2015, 37, 1-9.

14. Jaaskelainen, A.J.; Piiparinen, H.; Lappalainen, M.; Vaheri, A. Improved multiplex-PCR and microarray for herpesvirus detection from CSF. J. Clin. Virol. 2008, 42, 172-175. [CrossRef] [PubMed]

15. Kusum, S.; Aman, S.; Pallab, R.; Kumar, S.S.; Manish, M.; Sudesh, P.; Subhash, V.; Meera, S. Multiplex PCR for rapid diagnosis of tuberculous meningitis. J. Neurol. 2011, 258, 1781-1787. [CrossRef] [PubMed]

16. Wang, X.; Theodore, M.J.; Mair, R.; Trujillo-Lopez, E.; Du Plessis, M.; Wolter, N.; Baughman, A.L.; Hatcher, C.; Vuong, J.; Lott, L.; et al. Clinical validation of multiplex real-time PCR assays for detection of bacterial meningitis pathogens. J. Clin. Microbiol. 2012, 50, 702-708. [CrossRef] [PubMed]

17. Zhang, P.; Wang, H.; Guo, Z.; Yang, R.; Zhang, L. Advances in research on multiple biological detecting technologies. Milit. Med. Sci. 2012, 36, 713-717. [CrossRef]

18. Fraiture, M.A.; Herman, P.; Taverniers, I.; De Loose, M.; Deforce, D.; Roosens, N.H. Current and new approaches in GMO detection: Challenges and solutions. BioMed Res. Int. 2015, 2015, 392872. [CrossRef] [PubMed]

19. Korczak, B.; Frey, J.; Schrenzel, J.; Pluschke, G.; Pfister, R.; Ehricht, R.; Kuhnert, P. Use of diagnostic microarrays for determination of virulence gene patterns of Escherichia coli K1, a major cause of neonatal meningitis. J. Clin. Microbiol. 2005, 43, 1024-1031. [CrossRef] [PubMed]

20. Dunbar, S.A.; Van der Zee, C.A.; Oliver, K.G.; Karem, K.L.; Jacobson, J.W. Quantitative, multiplexed detection of bacterial pathogens: DNA and protein applications of the Luminex LabMAP system. J. Microbiol. Meth. 2003, 53, 245-252. [CrossRef]

21. Tait, B.D.; Hudson, F.; Cantwell, L.; Brewin, G.; Holdsworth, R.; Bennett, G.; Jose, M. Review article: Luminex technology for HLA antibody detection in organ transplantation. Nephrology 2009, 14, 247-254. [CrossRef] [PubMed]

22. Lynch, H.E.; Sanchez, A.M.; D’Souza, M.P.; Rountree, W.; Denny, T.N.; Kalos, M.; Sempowski, G.D. Development and implementation of a proficiency testing program for luminex bead-based cytokine assays. J. Immunol. Meth. 2014, 409, 62-71. [CrossRef] [PubMed]

23. Bai, X.; Liu, Z.; Ji, S.; Gottschalk, M.; Zheng, H.; Xu, J. Simultaneous detection of 33 streptococcus suis serotypes using the luminex xTAG(r) assay. J. Microbiol. Meth. 2015, 117, 95-99. [CrossRef] [PubMed]

24. Dunbar, S.A. Applications of luminex xmap technology for rapid, high-throughput multiplexed nucleic acid detection. Int. J. Clin. Chem. 2006, 363, 71-82. [CrossRef] [PubMed]

25. Moller, J.K. Detection of neisseria meningitidis in cerebrospinal fluid using a multiplex PCR and the luminex detection technology. Meth. Mol. Biol. 2012, 799, 37-53.

26. Pabbaraju, K.; Wong, S.; Tokaryk, K.L.; Fonseca, K.; Drews, S.J. Comparison of the luminex xTAG respiratory viral panel with xtag respiratory viral panel fast for diagnosis of respiratory virus infections. J. Clin. Microbiol. 2011, 49, 1738-1744. [CrossRef] [PubMed]

27. Taniuchi, M.; Verweij, J.J.; Noor, Z.; Sobuz, S.U.; Lieshout, L.; Petri, W.A., Jr.; Haque, R.; Houpt, E.R. High throughput multiplex PCR and probe-based detection with luminex beads for seven intestinal parasites. Am. J. Tropic. Med. Hyg. 2011, 84, 332-337. [CrossRef] [PubMed]

28. Li, Y.Q.; Duan, Z.J. Application of luminex xMAP technology in infectious diseases. Chin. J. Virol. 2010, 26, 158-161. [CrossRef] [PubMed] 
29. Chen, P.; Shi, M.; Feng, G.D.; Liu, J.Y.; Wang, B.J.; Shi, X.D.; Ma, L.; Liu, X.D.; Yang, Y.N.; Dai, W.; et al. A highly efficient ziehl-neelsen stain: Identifying de novo intracellular Mycobacterium tuberculosis and improving detection of extracellular M. tuberculosis in cerebrospinal fluid. J. Clin. Microbiol. 2012, 50, 1166-1170. [CrossRef] [PubMed]

30. Feng, G.D.; Shi, M.; Ma, L.; Chen, P.; Wang, B.J.; Zhang, M.; Chang, X.L.; Su, X.C.; Yang, Y.N.; Fan, X.H.; et al . Diagnostic accuracy of intracellular mycobacterium tuberculosis detection for tuberculous meningitis. Am. J. Respir. Critic. Care Med. 2014, 189, 475-481. [CrossRef] [PubMed]

31. Fan, X.H.; Feng, G.D.; Yang, Y.N.; Dai, W.; Zhao, G. Diagnostic value of may grunwald giemsa staining of cerebrospinal fluid in patients with cryptococcal meningitis. J. Int. Neurol. Neurosurg. 2013, 40, 220-222.

32. Marais, S.; Thwaites, G.; Schoeman, J.F.; Torok, M.E.; Misra, U.K.; Prasad, K.; Donald, P.R.; Wilkinson, R.J.; Marais, B.J. Tuberculous meningitis: A uniform case definition for use in clinical research. Lancet Infect. Dis. 2010, 10, 803-812. [CrossRef]

33. Boving, M.K.; Pedersen, L.N.; Moller, J.K. Eight-plex PCR and liquid-array detection of bacterial and viral pathogens in cerebrospinal fluid from patients with suspected meningitis. J. Clin. Microbiol. 2009, 47, 908-913. [CrossRef] [PubMed]

34. Taniuchi, M.; Verweij, J.J.; Sethabutr, O.; Bodhidatta, L.; Garcia, L.; Maro, A.; Kumburu, H.; Gratz, J.; Kibiki, G.; Houpt, E.R. Multiplex polymerase chain reaction method to detect Cyclospora, Cystoisospora, and Microsporidia in stool samples. Diagn.Microbiol. Infect. Dis. 2011, 71, 386-390. [CrossRef] [PubMed]

35. Lee, W.M.; Grindle, K.; Pappas, T.; Marshall, D.J.; Moser, M.J.; Beaty, E.L.; Shult, P.A.; Prudent, J.R.; Gern, J.E. High-throughput, sensitive, and accurate multiplex PCR-microsphere flow cytometry system for large-scale comprehensive detection of respiratory viruses. J. Clin. Microbiol. 2007, 45, 2626-2634. [CrossRef] [PubMed]

36. Van der Vlugt, R.A.; Van Raaij, H.; De Weerdt, M.; Bergervoet, J.H. Multiplex detection of plant pathogens through the luminex magplex bead system. Meth. Mol. Biol. 2015, 1302, 283-299.

37. Booth, S.A.; Drebot, M.A.; Martin, I.E.; Ng, L.K. Design of oligonucleotide arrays to detect point mutations: Molecular typing of antibiotic resistant strains of Neisseria gonorrhoeae and Hantavirus infected deer mice. Mol. Cell. Probe. 2003, 17, 77-84. [CrossRef]

38. Chou, C.C.; Chen, C.H.; Lee, T.T.; Peck, K. Optimization of probe length and the number of probes per gene for optimal microarray analysis of gene expression. Nucl. Acid. Res. 2004, 32, e99. [CrossRef] [PubMed]

39. Binder, H.; Preibisch, S. Specific and nonspecific hybridization of oligonucleotide probes on microarrays. Biophys. J. 2005, 89, 337-352. [CrossRef] [PubMed]

40. Steel, A.B.; Levicky, R.L.; Herne, T.M.; Tarlo, M.J. Immobilization of nucleic acids at solid surfaces: Effect of oligonucleotide length on layer assembly. Biophys. J. 2000, 79, 975-981. [CrossRef]

41. Wilson, W.J.; Erler, A.M.; Nasarabadi, S.L.; Skowronski, E.W.; Imbro, P.M. A multiplexed PCR-coupled liquid bead array for the simultaneous detection of four biothreat agents. Mol. Cell. Prob. 2005, 19, 137-144. [CrossRef] [PubMed]

42. Jokela, P.; Piiparinen, H.; Mannonen, L.; Auvinen, E.; Lappalainen, M. Performance of the luminex xTAG respiratory viral panel fast in a clinical laboratory setting. J. Virol. Meth. 2012, 182, 82-86. [CrossRef] [PubMed]

(C) 2016 by the authors; licensee MDPI, Basel, Switzerland. This article is an open access article distributed under the terms and conditions of the Creative Commons by Attribution (CC-BY) license (http://creativecommons.org/licenses/by/4.0/). 